\title{
Correspondence
}

\section{Airway management in angiotensin converting enzyme inhibitor related angioedema}

To the Editor:

In their review of the anaesthetic implications of angiotensin converting enzyme inhibitors (ACEI) and angioedema, ${ }^{1}$ Sarkar et al. review a limited variety of airway management techniques. Rai et al. describe five patients with ACEI related angioedema, all requiring emergency airway control. ${ }^{2}$ Four patients had a tracheostomy, and three of these were performed following awake fibreoptic intubation.

Tracheal intubation in these cases may be difficult. In one series, two of 14 cases required emergency cricothyroidotomy following failed endotracheal intubation. The authors produced an airway management algorithm, which suggested fibreoptic intubation with emergency cricothyroidotomy or tracheostomy if trans-oral intubation fails. ${ }^{3}$

Our own experience of three patients with ACEI angioedema suggests that early pre-emptive cannula cricothyroidotomy is useful in this setting. We use the Ravussin cannula-over-needle technique (VBM, Sulz, Germany). Pre-emptive, precautionary cricothyroidotomy has been shown to be an effective "insurance policy" in a variety of airway pathologies. ${ }^{4}$ This allows immediate oxygenation and ventilation if the airway becomes further compromised, and provides an effective bridge to definitive management. If the patient can be oxygenated via a cannula cricothyroidotomy, then the airway can be secured by either an awake fibreoptic technique, direct laryngoscopy under general anesthesia, or by tracheostomy depending on the operator's expertise.

Once the airway has been secured, however, there is little to be gained in performing a tracheostomy, as airway edema from ACEI usually resolves within $48 \mathrm{hr}^{3}$

Avinash Kapoor MBBS

Paul Jefferson FRCA

David R. Ball MBBS

Dumfries and Galloway Royal Infirmary, Dumfries, UK

E-mail: paul.jefferson@nhs.net

Accepted for publication November 21, 2006.

\section{References}

1 Sarkar P, Nicholson G, Hall G. Brief review: angiotensin converting enzyme inhibitors and angioedema: anesthetic implications. Can J Anesth 2006; 53: 9941003.

2 Rai MR, Amen F, Idrees F. Angiotensin-converting enzyme inhibitor related angioedema and the anaesthetist. Anaesthesia 2004; 59: 283-9.

3 Chin AG, Newkirk KA, Davidson BJ, Burningham AR, Krowiak EJ, Deeb ZE. Angiotensin-converting enzyme inhibitor-induced angioedema: a multicenter review and an algorithm for airway management. Ann Otol Rhinol Laryngol 2001; 110: 834-40.

4 Gerig HJ, Schnider T, Heidegger T. Prophylactic percutaneous transtracheal catheterisation in the management of patients with anticipated difficult airways: a case series. Anaesthesia 2005; 60: 801-5.

\section{Reply:}

Thank you for the opportunity of replying to the letter of Dr. Kapoor and colleagues.

Dr. Kapoor and colleagues comment that we have reviewed a limited number of airway management techniques in patients with angiotensin converting enzyme inbibitors (ACEI) related angioedema and suggest that early pre-emptive cannula cricothyroidotomy may be useful. This is based on their own experience of three patients in three years. ${ }^{1}$ It would be helpful if Dr. Kapoor and colleagues included some clinical details about their patients including presenting signs and symptoms as well as rapidity of diagnosis.

The purpose of our review was not to discuss emergency airway management techniques, but to increase awareness amongst clinicians of the risk of angioedema in patients on ACEI drugs. We again emphasize that initial diagnosis of the condition is most important. Securing the airway is the mainstay of successful management and this may indeed require a tracheostomy. Cannula cricothyroidotomy is a well recognized useful technique in the short term, but is not an effective substitute for securing a definitive airway.

Grainne Nicholson MB BS

George Hall PhD

St George's Hospital Medical School, London, UK

E-mail: gnichols@sgul.ac.uk 


\section{Reference}

1 Gerig HJ, Schnider T, Heidegger T. Prophylactic percutaneous transtracheal catheterisation in the management of patients with anticipated difficult airways: a case series. Anaesthesia 2005; 60: 801-5.

\section{International variances in carbon dioxide absorbent colour indicators}

To the Editor:

We recently provided general anesthesia to 16 children undergoing patent ductus arteriosus repair at the Angkor Wat Hospital for Children in Siem Reap, Cambodia. Prior to the first surgery, a thorough machine check was conducted, which demonstrated proper functioning of all elements, including the $\mathrm{CO}_{2}$ absorbent, which was uniformly white in colour. Midway through the first case, it was noted that in spite of adequate minute ventilation with a tidal volume of $10 \mathrm{~mL} \cdot \mathrm{kg}^{-1}$, that the $\mathrm{PETCO}_{2}$ ranged from $50-55 \mathrm{mmHg}$, and that during inspiration the $\mathrm{PETCO}_{2}$ decreased to only $12 \mathrm{mmHg}$. We suspected incomplete $\mathrm{CO}_{2}$ absorption.

Upon investigation, and much to our surprise, we learned that the fresh Spherasorb $\mathrm{CO}_{2}$ absorbent (Intersurgical Ltd., Wokingham, UK) was pink in colour and turned white with exhaustion. After the $\mathrm{CO}_{2}$ canister was filled with fresh soda lime, the patient's hypercapnia resolved. The confusion originated from our assumption that fresh $\mathrm{CO}_{2}$ absorbent is always white, which is the case at our home institution, in San Diego, California. In fact, Spherasorb has two types of indicators: one that changes from white to violet, and one that changes from pink to white. In contrast, Baralyme (Chemtron Medical Division, Allied Healthcare Products, St. Louis, MO, USA) has a single formulation that turns the crystals from white to violet with exhaustion.

It appears that the two colour schemes (pink to white, and white to violet), developed independently of each other many decades ago, as different $\mathrm{pH}$ sensitive dyes were used as markers for exhausted absorbent. While the American and European manufacturers chose the white to violet route (using ethyl violet dye), in the United Kingdom the pink to white option is employed (using titan yellow dye). ${ }^{1}$

According to Intersurgical Ltd., countries that use soda lime with a pink to white colour change include: the United Kingdom, much of Australia, New Zealand, India, Pakistan, Bangladesh, Hong Kong (which influenced China), Indonesia, Malaysia, and Sri Lanka. (all countries with a British colonial link.) Most other countries use soda lime that turns from white to violet with absorbent depletion. An additional factor to consider is that the $\mathrm{pH}$ and the resulting strength of colour depends on the moisture content of the exhausted soda lime. Higher exhaustion moisture content, as seen with low flows and large absorbers, results in a higher $\mathrm{pH}$ and weaker colour change. ${ }^{2,3}$ In addition, if the soda lime remains in the absorber for 10-48 hr, some of the $\mathrm{NaOH}$ regenerates and the $\mathrm{pH}$ increases, changing the colour of the soda lime back to its "fresh" appearing colour. This is often mistaken for a regeneration of $\mathrm{CO}_{2}$ absorbing potential. Also, desiccated baralyme may turn a yellow colour, ${ }^{4}$ further complicating the use of colour as a visual reference to the adequacy of absorbent capacity. Thankfully, the use of capnography allowed us to search for, and solve the problem. The experience highlighted the importance for anesthesiologists undertaking work overseas, to recognize international variances in $\mathrm{CO}_{2}$ colour indicators and the need to identify the indicator as part of the routine preoperative machine check.

Gloria Cheng MD

Mark Greenberg MD

University of California San Diego, San Diego, USA

E-mail: mgreenbe@ucsd.edu

Accepted for publication December 1, 2006.

\section{References}

1 Gootjes P, Lagerweij E. Quality comparison of different CO2 absorbents. Anaesthetist 1981; 30: 261-4.

2 Tsuchiya $M$, Ueda $W$. Heat generation as an index of exhaustion of soda lime. Anesth Analg 1989; 68: 7837.

3 Ohrn M, Gravenstein N, Good ML. Duration of carbon dioxide absorption by soda lime at low rates of fresh gas flow. J Clin Anesth 1991; 3: 104-7.

4 Barth CD, Dunning MB 3rd, Bretscher L, Woeblck HJ. Barium hydroxide lime turns yellow after desiccation. Anesth Analg 2005; 101: 748-52.

\section{Fast-track ambulatory anesthesia: impact on nursing workload when analgesia and antiemetic prophylaxis are near-optimal}

To the Editor:

We were very interested in reading the excellent publications of Dr. Song et al. ${ }^{1}$ and Dr. Awad et al. ${ }^{2}$ from Dr. Chung's research group addressing bypass of the postanesthesia care unit (PACU bypass) after 